involvement, and 193 for cutaneous involvement. The group of treatments that most often induces a therapeutic response (in more than $75 \%$ of cases) includes Ibandronate, Etanercept, Anakinra, Infliximab, Pamidronate and Adalimumab. Pamidronate, which represents the largest subpopulation in our study, has the highest weighted index of efficacy. Zoledronic acid, Lefulnomide, Ustekinumab and Methotrexate have less often induced a therapeutic effect (efficacy between $50 \%$ and $75 \%$ ) and Sulfasalazine and Secukinumab have response rates of less than $30 \%$. In total, bisphosphonates and TNF alpha antagonists have efficacy rates of $87.77 \%$ and $85 \%$ respectively. The weighted index, more than twice as high for bisphosphonates (42.96 versus 17.96), reflects the predominant use of these in SAPHO syndrome, with most often a beneficial effect. Conventional and synthetic targeted DMARDs and other biological treatments are less often effective in our study, with response rates of $47 \%$ and $58 \%$ respectively. The frequencies of each clinical manifestation were in agreement with the data of the literature. There was no clear clinical profile of a good responder to a particular treatment.

\begin{tabular}{lcccc}
\hline Therapeutic class & $\begin{array}{c}\text { Number of } \\
\text { patients }\end{array}$ & $\begin{array}{c}\text { Number of } \\
\text { responders }\end{array}$ & $\begin{array}{c}\text { Efficacy rate } \\
(\%)\end{array}$ & $\begin{array}{c}\text { Weighted } \\
\text { index }\end{array}$ \\
\hline $\begin{array}{l}\text { Bisphosphonates } \\
\text { Conventional }\end{array}$ & 139 & 122 & 87,77 & 42,96 \\
$\begin{array}{l}\text { DMARds } \\
\text { Synthetic targeted }\end{array}$ & 68 & 32 & 47,06 & 11,27 \\
drugs & 0 & NA & NA & NA \\
Anti TNF alpha & 60 & 51 & & \\
$\begin{array}{l}\text { Other biologics } \\
\text { TOTAL }\end{array}$ & 17 & 10 & 85 & 17,96 \\
& 284 & 215 & 58,82 & NA \\
\hline
\end{tabular}

Conclusions: This work made it possible to rank the different DMARDs used in the SAPHO syndrome. Anti TNF alpha and Pamidronate are the treatments that seem to bring the higher benefit.

Disclosure of Interest: None declared

DOI: 10.1136/annrheumdis-2018-eular.2714

\section{SAT0607 DRUGS USED OFF LABEL IN A RHEUMATOLOGY SERVICE OF A TERCIARY HOSPITAL}

D. Martinez-Quintanilla Jimenez ${ }^{1}$, N. García Castañeda ${ }^{1}$, P. Moreno Fresneda ${ }^{1}$, M. Perez Abanades ${ }^{2}$, R. Garcia De Vicuña ${ }^{1}$, I.G. Alvaro' ${ }^{1}$, E. Tomero Muriel ${ }^{1}$. ${ }^{1}$ Rheumatology; ${ }^{2}$ Hospital Pharmacy, Hospital La Princesa, Madrid, Spain

Background: The use of drugs off-label (DOL) is not uncommon in Rheumatology daily clinical practice for the treatment of patients with immune-mediated inflammatory diseases (IMID)

Objectives: To analyse the use of DOL requested by the Rheumatology Service. Methods: We reviewed the medical records of all patients registered in the DOL database of the Hospital Pharmacy Service between July 2009 and March 2017. The following variables were collected: date of approval and start of the drug physician, disease, reason for indication, sex and age of the patients, response to treatment according to the global assessment of the responsible physician, date and reason of withdrawal. A descriptive study of the variables collected through STATA 12 is carried out.

Results: 225 DOL were requested for a total of 174 patients. Women were $78.7 \%$, with an average age of 56.5 years (sd 1.15). In most patients (77\%) a single drug was requested. In 37 patients were requested between two $(16.4 \%)$ and seven drugs $(0.5 \%)$. The indications of the $\mathrm{DOL}$ in our database were: connective tissue diseases (CTD: $46.6 \%$ ), vasculitis (23\%), rheumatoid arthritis (RA: $5.2 \%)$ and spondyloarthritis (SPA:8\%). Other diseases (17.2\%) are included in two heterogeneous groups classified according to their ethiology (autoimmune $(8.6 \%$ ) or $\operatorname{not}(8.6 \%)$.

$39.5 \%$ of the drugs requested were conventional synthetic DMARDs (csDMARDs), $38.2 \%$ biological DMARDs (bDMARDs), $7.5 \%$ were antivirals, $2.6 \%$ vasodilators and $12 \%$ other drugs.

Conventional synthetic DMASDs (csDMARDs) represented $39.5 \%$ of request, biological DMARDs (bDMARDs) $38.2 \%$, antiviral drugs $7.5 \%$, vasodilator drugs $2.6 \%$ and other drugs $12 \%$.

Tables 1 and 2 show csDMARDs and bDMARDs respectively, according to the indication.

The effectiveness of the DOL was variable, ranging between $0 \%$ and $76.5 \%$. The most effective were antiviral drugs, used to treat viral infections in immunosuppressed patients $(76.5 \%)$, tocilizumab $(72.2 \%)$ and rituximab $(61.1 \%)$. By contrast, the least effective were anakinra $(0 \%)$ and TNF blockers $(31.8 \%)$. The $\underline{\mathrm{cs}}$ DMARDs group had an effectiveness of $53.9 \%$ (Mycophenolate stands out with $75 \%$ effectiveness).

The disease groups that responded best to $\mathrm{DOL}$ therapy were connective tissue and vasculitis, with $58 \%$ and $53.7 \%$ of effectiveness.
Abstract SAT0607 - Table 1

\begin{tabular}{lccccc}
\hline & RA & CTD & SPA & VASCULITIS & OTHERS $^{1}$ \\
\hline APREMILAST(\%) & 0 & 0 & 50 & 0 & 0 \\
CYCLOPOHSPHAMIDE & 28.6 & 1.9 & 0 & 0 & 16.7 \\
(\%) & & & & & \\
CYCLOSPORINE(\%) & 14.3 & 7.7 & 0 & 4.6 & 16.7 \\
LEFLUNOMIDE(\%) & 0 & 1.9 & 50 & 45.5 & 16.7 \\
MYCOPHENOLATE(\%) & 42.9 & 86.5 & 0 & 50 & 50 \\
TACROLIMUS(\%) & 14.3 & 1.9 & 0 & 0 & 0 \\
\hline
\end{tabular}

Abstract SAT0607 - Table 2

\begin{tabular}{lccccc}
\hline & RA & CTD & SPA & VASCULITIS & OTHERS $^{1}$ \\
\hline $\begin{array}{l}\text { ABATACEPT } \\
\text { (\%) }\end{array}$ & 0 & 0 & 7.7 & 3.9 & 16.7 \\
ANAKINRA(\%) & 0 & 0 & 0 & 0 & 25 \\
TNF blockers & 0 & 6 & 53.9 & 30.8 & 41.7 \\
$\begin{array}{l}\text { (\%) } \\
\text { RITUXIMAB(\%) }\end{array}$ & 0 & 87.9 & 0 & 26.9 & 0 \\
TOCILIZUMAB & 100 & 3 & 23.1 & 38.5 & 16.7 \\
$(\%)$ & & 0 & 15.4 & 0 & 0 \\
$\begin{array}{l}\text { USTEKINUMAB } \\
\text { (\%) }\end{array}$ & 0 & 0 & & & \\
\hline
\end{tabular}

${ }^{1}$ Others: other diseases mediated by immune mechanisms

Conclusions: Rheumatic diseases for which DOL is most commonly requested are connective tissue and vasculitis, as a consequence of the absence of specific indications for these pathologies. In our experience, rituximab is a good option in the treatment of connective tissue diseases, which contrasts with the results of some clinical trials. Tocilizumab is a good therapeutic option in the treatment of vasculitis, a group that includes Giant Cell Arteritis, as recently confirmed with its approval for this indication.

Disclosure of Interest: None declared

DOI: 10.1136/annrheumdis-2018-eular.6536

\section{SAT0608 HOW TO DIFFERENTIATE ADULT ONSET STILL'S DISEASE FROM OVERALL OTHER CAUSES OF FEVER OF UNKNOWN ORIGIN: RESULTS OF A PROSPECTIVE STUDY FROM A TERTIARY REFERRAL CENTRE}

E. Bilgin ${ }^{1}$, A. Erden², B. Armagan², L. Kılıç², A. Sarı², G. Yardımcı², M.K. Hayran ${ }^{3}$, A. Akdoğan ${ }^{1}$, Ö. Karadağ ${ }^{2}$, S. Apraş Bilgen ${ }^{2}$, I. Ertenli ${ }^{2}$, S. Kiraz ${ }^{2}$, U. Kalyoncu².

${ }^{1}$ Internal Medicine; ${ }^{2}$ Internal Medicine, Division of Rheumatology; ${ }^{3}$ Prevantive Oncology, Hacettepe University Faculty of Medicine, Ankara, Turkey

Background: Adult onset Still's disease (AOSD) is a rare, auto-inflammatory disease that commonly presents as fever of unknown origin (FUO), and most common rheumatologic cause of FUO. Clinical and/or laboratory parameters that can discriminate AOSD from other causes of FUO need to be clarified in current literature.

Objectives: To determine clinical and/or laboratory parameters that help to differentiate AOSD from other causes of FUO and demonstrating a clinician-friendly algorithm for this purpose.

Methods: Data from patients who admitted to Hacettepe University Hospitals inpatients sections of department of internal medicine with the complaint of FUO who eventually had a certain diagnosis, collected prospectively during 30 months. AOSD patients followed at Hacettepe University department of rheumatology were included. Clinical and laboratory data were collected at the time of diagnosis of AOSD and time of admission of patients with FUO.

Results: Total 156 patients ( $n=69$, for $A O S D ; n=87$, for FUO) were included. FUO group were also divided into three subgroups: rheumatologic $(n=31,35.6 \%)$ infectious $(n=28,32.2 \%)$ and malignant $(n=28,32.2 \%)$ causes. While $51(74 \%)$ patients were female in AOSD group, 43 (49,4\%) patients were female in FUO group $(\mathrm{p}=0.03)$. Frequency of rash, arthralgia, arthritis, sore throat, fever at night $(p<0.001$ for each), history of hemophagocytosis $(p=0.037)$ were significantly higher in AOSD group. Fever peak number equal and/or higher than 3, presence of lymphadenopathy ( $p=0002$ and $p=0,001$, respectively) were significantly higher in FUO group. While leukocytosis, neutrophilia, thrombocytosis, hyperferritinemia, higher lactate dehydrogenase and complement 3 levels $(p<0.001$ for each) were significantly more frequent in AOSD group, albumin levels lower than $3 \mathrm{~g} / \mathrm{dl}$ and positive rheumatoid factor ( $p=0.009$ and $p=0.002$, respectively) were significantly more frequent in FUO group. Results of univariate and multivariate analysis are given in table 1. Algorithm for discrimination of AOSD and FUO is given at Abstract SAT0608-figure 1. 
Abstract SAT0608 - Table 1. Results of univariate and multivariate analysis

\begin{tabular}{lcccccc}
\hline & \multicolumn{3}{c}{ Univariate Analysis } & \multicolumn{3}{c}{ Multivariate Analysis } \\
\hline Variables & $\begin{array}{c}\text { Odds } \\
\text { Ratio }\end{array}$ & $\begin{array}{c}\text { Confidence } \\
\text { Interval }\end{array}$ & $\begin{array}{c}\mathbf{p} \\
\text { value }\end{array}$ & $\begin{array}{c}\text { Odds } \\
\text { Ratio }\end{array}$ & $\begin{array}{c}\text { Confidence } \\
\text { Interval }\end{array}$ & $\begin{array}{c}\mathbf{p} \\
\text { value }\end{array}$ \\
\hline Favours Still's & & & & & & \\
Fever at night & 7,66 & $3,53-16,5$ & $<0001$ & & & \\
Rash & 10,08 & $4,80-21,2$ & $<0001$ & 31,3 & $3,6-271,9$ & $\mathbf{0 0 0 2}$ \\
Arthritis & 6,58 & $3,09-14,01$ & $<0001$ & & & \\
Arthralgia & 36 & $10,46-123,8$ & $<0001$ & 158,1 & $4,3-5755,8$ & 0006 \\
Sore throat & 27,72 & $11,58-66,33$ & $<0001$ & 20,8 & $2,8-154,7$ & 0003 \\
Hemophagocytosis & 4,79 & $0,96-23,89$ & 0079 & & & \\
Neutrophilia & 10,87 & $4,90-24,13$ & $<0001$ & 18,4 & $2,6-132,3$ & 0004 \\
Ferritin $\geq 5$ x UNL & 4,88 & $2,34-10,16$ & $<0001$ & 132,8 & $7,1-2502,9$ & 0001 \\
LDH & 7,12 & $2,35-21,59$ & $<0001$ & 6,2 & $0,76-50,9$ & 0087 \\
C3 & 3,20 & $1,47-7,00$ & 0003 & & & \\
Female & 2,90 & $1,46-5,73$ & 0002 & & & \\
Favours FUo & & & & & & \\
Pleuritis & 2,04 & $0,68-6,12$ & 0,19 & & & \\
Fever peak & 3,66 & $1,16-11,52$ & 0019 & 69 & $2,2-2114,4$ & 0015 \\
number $\geq 3$ & & & & & & \\
Lymphadenopathy & 3,39 & $1,72-6,79$ & $<0001$ & & & \\
\hline UNL: Upper normal limit (for ferritin: $336 \mathrm{ng} / \mathrm{ml})$ & & & & & \\
\end{tabular}

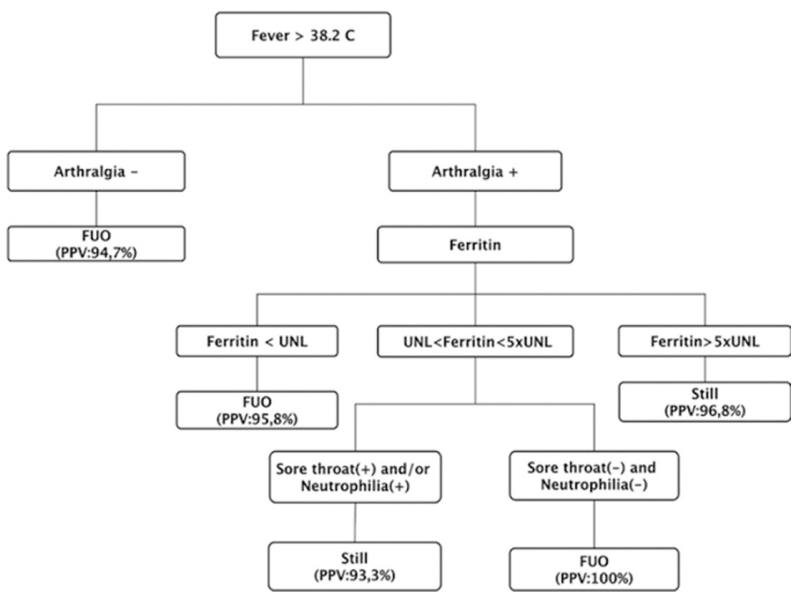

Conclusions: Presence of arthralgia, hyperferritinemia, sore throat and neutrophilia strongly favour AOSD in patients presenting as FUO. This study demonstrates a clinician-friendly algorithm for the first time in current literature.

Disclosure of Interest: None declared

DOI: 10.1136/annrheumdis-2018-eular.3786

\section{\begin{tabular}{|l|l}
\hline SAT0609 & VENOUS VESSEL WALL THICKNESS IN LOWER
\end{tabular} EXTREMITY IS INCREASED IN MALE BEHCET'S DISEASE PATIENTS WITH AND WITHOUT VASCULAR INVOLVEMENT}

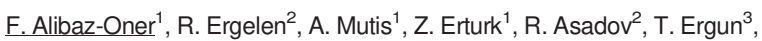
H. Direskeneli ${ }^{1}{ }^{1}$ Rheumatology; ${ }^{2}$ Radiology; ${ }^{3}$ Dermatology, Marmara University, School of Medicine, Istanbul, Turkey

Background: Vascular involvement is seen in up to $40 \%$ of the patients with Behcet's Disease (BD), especially in young males and is one of the major causes of mortality and morbidity. Lower extremity vein thrombosis due to vascular inflammation is the most frequent form of vascular involvement in BD. Recently, assessment of vessel wall thickness (VWT) and venous dilatation by US is suggested to be valuable in patients with vascular inflammation.

Objectives: In this study, we investigated whether vessel wall thickness or dilatation is present in young male BD patients prone to venous vascular disease.

Methods: Thirthy male patients with BD without major organ involvement and 29 male patients with Vascular BD(VBD) followed in Marmara University Behcet's Clinics, 24 healthy male controls and 27 male patients with Ankylosing Spondylitis (AS) were included the study. Bilateral lower extremity venous doppler ultrasonography (US) was performed by an experienced radiologist blinded to cases. No patients except VBD were under immunosuppressive treatment. Bilateral common femoral vein (CFV) wall thickness and great/small saphenous vein dilatations were examined. Behçet Syndrome Activity Score (BSAS) was used for the general assessment of disease activity. In 10 patients, CFV wall thickness was measured by 2 different radiologist (RE, RA) in the same day to calculate "interobserver reliability". Correlation between radiologists was good. ( $r=0.765$, $\mathrm{p}<0.001)$.
Results: The mean disease duration was $9.1 \pm 6$ years in patients with BD. BSAS score was $24 \pm 17$. All venous measurements were significantly higher in BD compared to $A S$ and healthy controls $(p<0.001$ for all, table 1$)$. When we compared mucucutaneous BD and VBD, all measurements of patients with VBD were higher than mucocutaneous BD. But only left CFV thickness and width of right great saphenous vein reached the statistical significance $(p<0.001$, an $p=0.028$, respectively, figure 1). There were no correlations between BSAS, acute phase reactants and venous wall measurements.

Abstract SAT0609 - Table 1. Venous wall measurements of lower extremity in study groups.

\begin{tabular}{|c|c|c|c|c|}
\hline & $\begin{array}{c}\text { Behçet's } \\
\text { Disease }(n=59)\end{array}$ & $\begin{array}{c}\text { Ankylosing } \\
\text { Spondylitis }(\mathrm{n}=27)\end{array}$ & $\begin{array}{c}\text { Healthy } \\
\text { Controls }(n=24)\end{array}$ & $\begin{array}{c}\mathrm{P} \\
\text { Value }\end{array}$ \\
\hline Age, years & $32.5(23-42)$ & $32(20-37)$ & $27.5(25-42)$ & 0.023 \\
\hline $\begin{array}{l}\text { Body Mass Index (kg/ } \\
\text { m2) }\end{array}$ & $25.1(18-33)$ & $25(18-32)$ & $23.8(20-29)$ & 0.213 \\
\hline $\begin{array}{l}\text { Right Common femoral } \\
\text { VWT }(\mathrm{mm})\end{array}$ & $0.8(0.04-1.8)$ & $0.3(0.1-0.6)$ & $0.25(0.06-0.4)$ & $<0.001$ \\
\hline $\begin{array}{l}\text { Left Common femoral } \\
\text { VWT }(\mathrm{mm})\end{array}$ & $0.8(0.3-1.6)$ & $0.3(0.1-0.5)$ & $0.2(0.04-0.6)$ & $<0.001$ \\
\hline $\begin{array}{l}\text { Right Great saphenous } \\
\text { width }(\mathrm{mm})\end{array}$ & $3.1(0-6.4)$ & $2.5(1.1-3.5)$ & $2.1(1.3-3.5)$ & $<0.001$ \\
\hline $\begin{array}{l}\text { Left Great saphenous } \\
\text { width }(\mathrm{mm})\end{array}$ & $3.1(0-7.4)$ & $2.6(0.3-4.8)$ & $2.4(1.6-3.6)$ & $<0.001$ \\
\hline $\begin{array}{l}\text { Right Small saphenous } \\
\text { width }(\mathrm{mm})\end{array}$ & $2.8(0-5.3)$ & $1.7(1-3.1)$ & $1.4(0.9-3.7)$ & $<0.001$ \\
\hline Left Small saphenous & $2.7(0-5.2)$ & $1.8(1.1-3.4)$ & $1.6(0.8-3.6)$ & $<0.001$ \\
\hline
\end{tabular}

width $(\mathrm{mm})$

VWT: Venous wall thickness

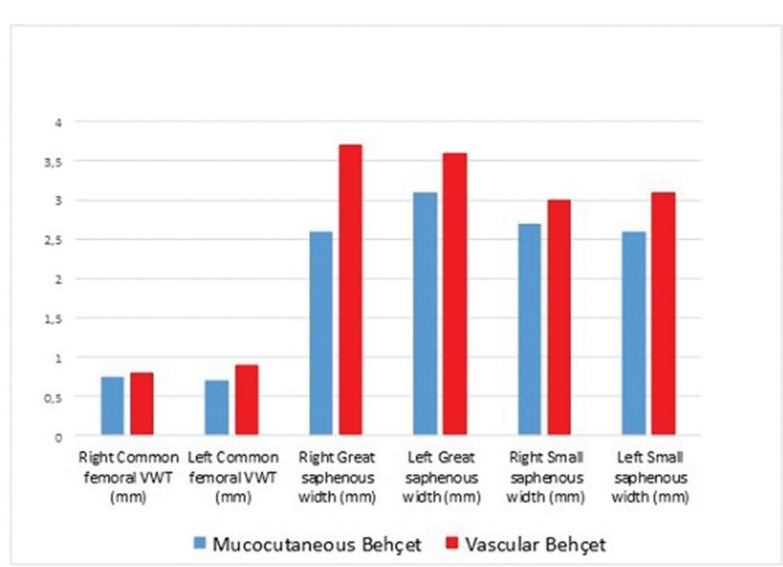

Abstract SAT0609 - Figure 1. Venous Vessel Assessments of patients with Mucocutaneous Behçet and Vascular Behçet

Conclusions: In our study, an increased venous vessel wall thickness in lower extremity was shown in male BD patients with or without vascular involvement. As a similar change was not observed in controls, we think, increased VWT might be an early sign of venous inflammation in patients with BD rather than a result of non-specific systemic inflammation.

Disclosure of Interest: None declared

DOI: 10.1136/annrheumdis-2018-eular.2858

\section{SAT0610 A DECLINING TREND IN FREQUENCY OF SECONDARY AMYLOIDOSIS IN BEHÇET'S SYNDROME}

G. Karatemiz, S.N. Esatoglu, Y. Ozguler, S. Yurdakul, V. Hamuryudan, I. Fresco, M. Melikoglu, E. Seyahi, S. Ugurlu, H. Ozdogan, H. Yazıcı, G. Hatemi.

Rheumatology, Istanbul University of Cerrahpasa Medical Faculty, Istanbul, Turkey

Background: A decline in the frequency of $A A$ amyloidosis secondary to rheumatoid arthritis and infectious diseases has been reported. This is probably due to more effective treatment strategies. We had previously reported that although amyloidosis occurs in less than $0.5 \%$ of BS patients, it is one of the leading causes of death. ${ }^{1-3}$ We had an impression that the frequency of amyloidosis is decreasing among our patients with BS.

Objectives: We aimed to determine the change in the frequency of AA amyloidosis over years in BS pts in addition to elaborating on clinical characteristics and outcomes. 